\title{
FIGURACIÓN Y REALIDAD DEL ESCRITOR LATINOAMERICANO EN LA ERA GLOBAL
}

Aníbal González

Yale University

\begin{abstract}
Quain solía argumentar que los lectores eran una especie ya extinta. No hay europeo (razonaba) que no sea un escritor, en potencia o en acto.
\end{abstract}

Jorge Luis Borges

A principios de la década de los 70 del siglo pasado, en un célebre ensayo, Roland Barthes proclamaba "la muerte del autor". Semejante declaración provocó al principio la perplejidad de sus lectores, pues quien la hacía era uno de los mayores autores de su país e integrante de una brillante constelación de ensayistas y pensadores. Y si bien la novela francesa de aquellos años andaba de capa caída, al otro lado del Atlántico la narrativa latinoamericana vivía la época heroica del boom, cuyos autores, con sus novelas deslumbrantes, acababan de desplazar en sus tierras la primacía de los poetas y se manifestaban más vivos y enérgicos que nunca.

Barthes se refería, claro está, al hecho hoy consabido de que la acción de escribir anula o desvanece al sujeto que escribe (1977: 143). Siguiendo a Flaubert y a Mallarmé, Barthes considera que toda escritura es, en rigor, impersonal y que el "autor" es solo una figuración impuesta al texto para marcarle límites interpretativos (1977: 147). Barthes concluye su ensayo, como es sabido, postulando que la "muerte del autor" abre paso al "nacimiento del lector" (1977: 148), aunque, como veremos dentro de poco, el lector -quien busca o le otorga sentido a un texto- es un ente no menos frágil y efímero.

Las monumentales novelas totalizadoras del boom se produjeron a partir de este concepto impersonal de la escritura, muy en armonía con el dictamen flaubertiano de que "el autor en su libro debe ser como Dios en el universo: presente en todas partes y visible en ninguna" (Flaubert 1980: 173). Más aún, estas novelas, desde La región más transparente, Rayuela y Tres tristes tigres hasta 
Paradiso, Cien años de soledad y La casa verde, se presentaban como textos de raíz colectiva, los cuales, a la vez que coordinaban múltiples tiempos y voces, parecían haber sido escritos desde la eternidad, y tenían un cariz sagrado, ritualista, que exigía una lectura atenta y un cuidadoso desciframiento. Esto no significa que no hubiese figuras autoriales en dichas novelas; sí las había, pero por lo general estas se mostraban debilitadas, moribundas, muertas o convertidas en figuras de leyenda, como es el caso con Ixca Cienfuegos, Morelli, Bustrófedon, Oppiano Licario, Melquíades, o el arpista Anselmo.

No obstante, si el autor en la novela del boom era un Dieu caché, una deidad oculta comunicándose a través de signos a veces enigmáticos, en la realidad referencial la situación era dramáticamente distinta: allí, una combinación de factores contribuyeron a la creación de un panteón viviente de autores que a menudo eran vistos como héroes de la cultura latinoamericana. En libros de entrevistas y ensayos como Los nuestros (1966), de Luis Harss, Narradores de esta América (1969), de Emir Rodríguez Monegal, y La nueva novela hispanoamericana (1969), de Carlos Fuentes, e incluso en la escéptica e irónica Historia personal del "Boom" (1972), de José Donoso, así como en el registro iconográfico de Sarah Facio y Alicia D'Amico, en Retratos y autorretratos: escritores de América Latina (1973), se fue forjando y cristalizando una nueva imagen del autor latinoamericano. Era una imagen que combinaba rasgos que a primera vista parecían incompatibles: juventud y experiencia, nacionalismo y cosmopolitismo, elitismo y populismo, seriedad y espíritu lúdico. Además, la impresión de unidad continental se veía reforzada por la frecuente aparición pública conjunta de estos autores en conferencias y encuentros, por los proyectos que realizaban a dúo o en grupos, e incluso por su opción de residir por largas temporadas en las mismas ciudades: Barcelona, México, París.

Se trataba de una situación cuyo mejor paralelo en la anterior literatura latinoamericana habría que buscarlo en el modernismo hispanoamericano, el primer momento en el que los escritores latinoamericanos alcanzaron fama y prestigio puramente en virtud de su oficio literario. No obstante, la diferencia entre los mecanismos de la celebridad de finales del siglo xIx y principios del xx y los de la segunda mitad del siglo xx era inmensa: para los años 1960, los periódicos y revistas ya formaban parte de un conglomerado de industrias que se conocerían con el nombre de "medios de masa", con un mercado y una difusión muchísimo mayores que los de la era modernista (Álvarez y Martínez 1992: 179-244). Una anécdota muy conocida refiere que García Márquez solo entendió el alcance de su fama cuando en 1967 vio en Buenos Aires su imagen repetida en las portadas de la revista Primera Plana en los quioscos callejeros, y después cuando vio una mujer que salía del mercado cargando una bolsa en la que había un ejemplar de Cien años de soledad entre las lechugas y los tomates (Saldívar 1997: 455).

La imagen pública del autor latinoamericano a partir del boom rebasa pues los estrechos límites de la tertulia literaria de las élites, de los debates y análisis de la academia, o incluso de la tarima de los políticos, para ocupar un espacio a medio camino entre el intelectual y la estrella de cine. Sin lugar a dudas, el autor del boom que mejor ejemplificó este modelo fue Carlos Fuentes, 
con su apostura de galán de película mexicana (y sus contactos directos con esa industria a través de su primera esposa, la actriz Rita Macedo), sus sesudos ensayos sobre temas literarios, culturales y políticos, y las rumbosas fiestas en su casa por donde pululaba, en palabras de José Donoso, "toda la picaresca literario-plástica-cinematográfica-teatral-social de México, además de internacional" (1983: 82).

Claro está, todo este glamour, toda esta proyección mediática y cercanía al poder, se justificaba en última instancia por los atributos de aquellas novelas que, a pesar de que simulaban no tener autor, ser completamente autónomas, emanadas mágicamente de una voz comunal, revertían de nuevo hacia sus autores de carne y hueso y los transformaban en otra cosa: dobles, avatares, simulacros, íconos (y la veneración que esto último implica). En los albores del boom, y años antes del ensayo de Barthes, Jorge Luis Borges lo vio con su habitual clarividencia en materia de la escritura en su texto "Borges y yo", cuando señala que su álter ego literario comparte sus preferencias -"los relojes de arena, los mapas, la tipografía del siglo xVIII, las etimologías, el sabor del café y la prosa de Stevenson"- "pero de un modo vanidoso que las convierte en atributos de un actor" y añade que le consta la "perversa costumbre de falsear y magnificar" de su doble textual (1996b: 186). Para Borges, la muerte del autor no implica tanto el nacimiento del lector como el nacimiento de otro tipo de autor, distinto del "creador" patriarcal que engendraba a su obra. Este nuevo autor no es el "padre" de su obra, sino más bien el "hijo" de ella: una nueva versión, vanidosa, falsa y magnificada, del falible ser humano que sirvió de vehículo, de mero "hacedor", para la obra artística. Entre las narraciones del boom y los individuos que las escribieron se forjó entonces una especie de "círculo virtuoso" (como dirían los economistas), en vez de "vicioso", en el cual la fama de la obra engrosaba el prestigio del autor y el prestigio del autor reforzaba la fama de la obra, y este ciclo nos ayuda a entender la energía con la cual se promovió durante los años 60 la imagen heroica del autor latinoamericano.

A su vez, la visión del autor latinoamericano como héroe cultural a partir de los años 1960 se vincula con los inicios del proceso de globalización más reciente de la literatura de América Latina. (Especifico que se trata del "más reciente", pues puede argumentarse que la literatura latinoamericana -particularmente en Hispanoamérica- experimentó su primera globalización durante el movimiento modernista. $)^{1}$ Esta globalización ha sido consecuencia en gran medida de algunos procesos que ya se venían dando desde principios del siglo xx en la economía mundial y que últimamente se han venido intensificando, tras verse interrumpidos y obstaculizados por dos guerras mundiales y por la "guerra fría" entre capitalismo y comunismo, que terminó con la caída del Muro de Berlín en 1989. Me refiero a procesos tales como la apertura de mercados internacionales, la desreglamentación y privatización de industrias y servicios, y la aplicación de tecnologías cada vez más avanzadas de telecomunicación y cibernética.

\footnotetext{
${ }^{1}$ Véanse más pormenores sobre el modernismo como fenómeno "proto-globalizado" en el primer capítulo de Aníbal González (2007).
} 
Dentro de estos procesos de globalización, la proyección heroica del canon del boom latinoamericano a través de los medios de masa y la industria publicitaria conoció otro efecto paradójico: mientras más circulaban las imágenes y noticias de las ejecutorias de los autores del boom, más se veían expuestos a los riesgos de la celebridad en la era posmoderna, pues en medio de la insistente cobertura mediática de sus idas y venidas, de sus polémicas políticas y personales - desde el Caso Padilla hasta el puñetazo que le propinó Vargas Llosa a García Márquez-, y de sus empresas no-literarias (sus incursiones en el cine y la televisión, por ejemplo), comenzaba a trivializarse y a desgastarse cada vez más el estatuto heroico del autor latinoamericano.

Conviene recordar, asimismo, que el propio boom no había sido una explosión sin secuela, sino que, al contrario, había desatado una enorme productividad literaria que abrió paso a grupos subsiguientes de escritores con nuevos proyectos y agendas artísticas. La crítica ensayó varios términos para estos autores surgidos en la estela del boom, desde el "boom junior" (nombre que no "pegó") hasta el más usado pero incoloro "posboom". Hoy día se reconoce que el posboom representó una extraordinaria diversificación de acercamientos a la ficción narrativa: las narraciones de experimentación lingüística y semiótica de Severo Sarduy y Manuel Puig, la narrativa testimonial y documental de Miguel Barnet, Elena Poniatowska y Rigoberta Menchú, la boga de la nueva novela histórica que culminó en el Quinto Centenario, la nueva novela negra de Paco Ignacio Taibo II y Leonardo Padura Fuentes, y la nueva novela sentimental encabezada por Alfredo Bryce Echenique ${ }^{2}$. No menos importante fue el mayor acceso al mercado editorial que esta variedad novelística les dio a las narradoras latinoamericanas - desde Isabel Allende y Ángeles Mastretta hasta Diamela Eltit y Carmen Boullosa (Pellón 1996: 300-301)-. Dicho acceso corrió parejo con un rasgo común en gran parte de la narrativa del posboom, que fue el énfasis en las identidades. Nótese que utilizo el plural, pues no se trataba ya tanto de la manida cuestión de la identidad nacional latinoamericana, sino de la mayor representación de grupos sociales antes marginados dentro del panorama literario: mujeres, homosexuales, indígenas, afrodescendientes y miembros de otras etnicidades (Pellón 1996: 280-281).

A su vez, como parte de su representación de las identidades sociales, el posboom prestó mayor atención que el boom a la subjetividad individual, a las necesidades, experiencias, cuitas, derrotas y triunfos de individuos sumamente particularizados, desde el cimarrón Esteban Montejo y la indígena Rigoberta Menchú hasta el detective Mario Conde y el escritor enamorado Martín Romaña. Efectivamente, los autores y autoras del posboom hicieron caso omiso de la tradición de la impersonalidad novelística, y sin caer en falacias románticas acerca de la expresión literaria del "Yo", aceptando que la subjetividad es algo construido,

\footnotetext{
2 Consúltense al respecto los estudios de Gutiérrez-Mouat (1988), Pellón (1996) y Shaw (1994, 1998). A las tres corrientes del posboom que identifica Pellón (la novela testimonio, la novela histórica y la policial, 1996: 282), habría que añadir, sin lugar a dudas, las otras dos que señala Shaw (1998: 23-24): la que podría llamarse "neovanguardista" (de Sarduy a Eltit) y la amorosa-sentimental. Véase también González (2010).
} 
procedieron a construirse diversas subjetividades a lo largo de sus narraciones (González 2010: 1-39).

Algunos incluso tomaron el rumbo de la "autoficción", es decir, la inscripción de personajes con nombres y rasgos muy semejantes o idénticos a los de su autor aunque con propósitos mayormente ficcionales ${ }^{3}$. Aunque la autoficción es una antigua práctica literaria que se remonta hasta la Edad Media europea, en Latinoamérica Borges fue el precursor inmediato más prominente de esta técnica, en cuentos como "Tlön, Uqbar, Orbis Tertius", "El Aleph" y "Borges y yo" (Schlickers 2010: 51-71; Covarsí 2010: 97-110). Conviene notar, empero, que en la mayor parte de la narrativa del posboom, como en la de Borges, esa súbita presencia del autor en medio de su narración no era ya una manifestación de egoísmo como lo había sido en el siglo xIX o a principios del siglo $\mathrm{xx}$, sino un gesto mucho más modesto y autocrítico. Por ejemplo, en La vida exagerada de Martín Romaña (1985) de Bryce Echenique, otro influyente modelo de la autoficción latinoamericana, un personaje Ilamado Alfredo Bryce Echenique persigue e importuna al protagonista, Martín, quien lo detesta cordialmente (Bryce 1987: 187, 500-503). En otros escritores, en vez de esta suerte de desdoblamiento encontramos más frecuentemente la imagen de un autor que no solo es un personaje más de la ficción, sino que a menudo se muestra perplejo e inseguro de su estatuto de autoridad o incluso de su capacidad de narrar con claridad los acontecimientos que el texto refiere: así lo vemos desde novelas como La Habana para un infante difunto (1979) de Guillermo Cabrera Infante hasta Santa Evita (1995) de Tomás Eloy Martínez y En busca de Klingsor (1999) de Jorge Volpi.

Hasta los autores del boom demostraron su versatilidad y una sorpresiva humildad artística al seguir la nueva figuración del autor propuesta por el posboom en sus narraciones de fines de los años 1970 en adelante. Así, en 1977 Vargas Llosa publica la primera y más explícita de sus representaciones autoficcionales en La tía Julia y el escribidor, donde el autor de narraciones monumentales como La casa verde y Conversación en La Catedral baja de su pedestal y asume el mote de "Varguitas", burlándose de sí mismo y de sus ingenuidades juveniles, a la vez que busca entroncar su ficción con los medios de masa y la cultura popular. Por su parte, en Crónica de una muerte anunciada (1981) de García Márquez, el personaje y narrador en primera persona, que en función de autor intenta inútilmente aclarar las circunstancias del asesinato de Santiago Nasar, confiesa avergonzado que a la hora en que mataban a su amigo él estaba reponiéndose de la parranda de la boda "en el regazo apostólico de María Alejandrina Cervantes" (1981: 11) y por ello no pudo intervenir para salvarlo.

Entre todos los autores del posboom, la autoficción alcanza una intensidad casi paroxística en la obra de Fernando Vallejo, cuyo entrelazamiento de autobiografía y ficción es tan apretado como el de Bryce Echenique, pero que

\footnotetext{
${ }^{3}$ La bibliografía sobre la autoficción ha venido creciendo poco a poco en la última década en los estudios de literatura hispánica e hispanoamericana a partir de los estudios en literatura francesa que originaron el concepto (Lejeune 1975, Darrieussecq 1996, Gasparini 2008). En la crítica de las literaturas hispánicas se destacan los trabajos de Molero de la Iglesia (2000), Alberca (2007) y la antología de ensayos coordinada por Toro, Schlickers y Luengo (2010).
} 
resulta aún más llamativo por el tono polémico de sus novelas. Si bien es cierto que la autoficción cumple múltiples y diversas funciones en los textos que la utilizan - desde una máscara autorial hasta una suerte de "firma" implícita del autor incorporada al texto narrativo- (Chihaia 2010: 141-153), en Vallejo la autoficción ciertamente vuelve borrosas las fronteras entre la figuración del autor y el autor de carne y hueso ${ }^{4}$, poniendo de relieve entonces la estrategia de sistemática contradicción mediante la cual Vallejo se opone a la tendencia moderna a convertir los textos literarios - particularmente las novelas- en textos sagrados y a los autores en héroes o profetas.

Como se sabe, el personaje-narrador de Vallejo (que suele ser el mismo desde Los días azules, de 1985, hasta El don de la vida, de 2010) asume una postura de sistemática contrariedad a todo lo que sea o parezca ser favorecido o desfavorecido por la mayoría de su público lector: así, el narrador vallejiano dice despreciar todo tipo de religión, además de la democracia y el populismo, la nación en general y en particular (es decir, Colombia), el sexo por procreación y la vida humana en general; por otra parte, afirma su ateísmo (aunque en los ambiguos términos de la blasfemia), su postura más egoísta que elitista ante las masas, su desarraigo, su pederastia, su amor por los animales y su nihilismo. No se trata, a mi parecer, de la simple y llana inversión de valores que han practicado los poetas y prosistas "malditos" de los siglos XIX y XX, desde Baudelaire hasta Jean Genet, la cual ha llevado a algunos a crear en torno a estos autores una sacralidad de signo negativo. Se trata más bien, de una estrategia de "ofender a todos por igual" para no permitir que sus textos sean sacralizados -es decir, vistos como fuente de revelación- ni que su persona sea vista como la de un vates o un profeta.

En no pocos de los autores y autoras latinoamericanos posteriores al posboom, a quienes tal vez podríamos Ilamar "los del Milenio", en vista de que muchos alcanzan mayor visibilidad en la transición al siglo xxı, podemos ver una prolongación de esta actitud con respecto a la figura autorial en la ficción. Los del Milenio han adoptado con naturalidad la autoficción como una de sus prácticas preferidas, afianzando de este modo en las últimas décadas la figuración literaria del autor como un personaje autocrítico, dubitativo y dudoso, a veces algo fantasmal, aunque siempre inseparablemente entretejido con su texto.

Los detectives salvajes de Roberto Bolaño -uno de los autores tutelares del grupo del Milenio- se apoya consistentemente en esta técnica a través de la figura de Arturo Belano, un poeta chileno radicado en México quien, en compañía del poeta mexicano Ulises Lima, protagoniza un relato que se va revelando fragmentariamente a través de los recuerdos a menudo borrosos y digresivos de los múltiples individuos que tuvieron que ver con ellos a lo largo de dos décadas. Los elementos autoficcionales que hacen de Belano un evidente álter ego de Bolaño, aparte de la similitud fónica de sus nombres, van desde su origen chileno y su residencia en México y Cataluña hasta su duelo en una playa con el crítico Iñaki Echavarne (álter ego en la novela de Ignacio Echevarría, amigo y luego

\footnotetext{
${ }^{4}$ Un estudio pormenorizado de la autoficción en Vallejo es el de Villena Garrido (2009).
} 
albacea literario de Bolaño) y los medicamentos que Belano tomaba en África para cuidarse de una pancreatitis, entre muchos otros. Con todo, aunque se le ha comparado con Rayuela de Cortázar - probablemente debido al retrato grupal que ofrece de la bohemia artística-, en Los detectives salvajes el personaje de Arturo Belano resulta ser mucho más enigmático y esquivo que Horacio Oliveira en la novela de Cortázar. Vale la pena observar que entre el coro de monólogos de Los detectives salvajes no hay ninguno perteneciente al propio Belano ni a su cuate Ulises Lima. Los múltiples interlocutores de Belano, incluyendo a sus cuatro amantes, no parecen conocerlo bien del todo ni entender sus motivaciones. Belano y Lima son, de hecho, dos figuras autoriales en fuga, las cuales, tras su fallido intento de descubrir los secretos de la poesía, buscan sencillamente desaparecer, o como le dice Belano a Jacobo Urenda, "hacerse matar" (Bolaño 2009: 529). Por otro lado, Los detectives salvajes está repleta de figuras de autoridad caducas y degradadas, desde el poeta estridentista Manuel Maples Arce hasta Octavio Paz, sin mencionar lo que le sucede a la tan buscada poetisa Cesárea Tinajero, que es el objeto de las pesquisas detectivescas de Belano y Lima.

En contraste, en Los informantes (2004) de Juan Gabriel Vásquez, el personaje-narrador Ilamado Gabriel Santoro es una presencia vívida y central en este relato de intrigas y traiciones asociadas a los vínculos de nazis y filonazis con el gobierno colombiano durante los años cuarenta, hechos poco conocidos en Colombia hasta la aparición de esta novela. Aludiendo al "adelgazamiento de la distancia que existe entre el autor y el narrador" en su novela, Vásquez afirma en una entrevista:

\begin{abstract}
Aquí, deliberadamente yo construí un narrador lo más parecido a mí posible, como medio de decirle al lector: "estoy comprometido moral y emocionalmente con la historia, yo me pongo en la línea de fuego, yo estoy desechando -hasta cierto punto- las máscaras de la ficción". Entonces, el crear un personaje que algunos lectores pudiesen identificar conmigo, era una manera de hacerle ver al lector que en este libro hay un grado de verosimilitud que no puede pasar por alto, hay un alto grado de realidad en los hechos que se cuentan. (Salazar 2013)
\end{abstract}

No obstante, pese a su centralidad en Los informantes, el personaje de Gabriel dista mucho de ser un autor prepotente que controla absolutamente su relato. Más bien resulta lo contrario: periodista de profesión, Gabriel es un retransmisor de historias ajenas, no un forjador de ficciones autónomas, pues ha publicado un libro sobre las vicisitudes de la comunidad judía en Colombia durante la Segunda Guerra Mundial basado en entrevistas con Sara Guterman, una amiga de su padre. En Los informantes, Vásquez literaliza la figura del "autor como hijo" sugerida por "Borges y yo", pero la coloca en una situación que recuerda más bien la tesis de Harold Bloom acerca de la "ansiedad de la influencia": el padre de Gabriel, que lleva su mismo nombre, es un austero profesor de oratoria y maestro de retórica que ha publicado una reseña demoledora del primer libro de su hijo poco tiempo antes de morir en un accidente de automóvil. A través de la novela se nos presenta la investigación que lleva a cabo 
el narrador-protagonista de los motivos que llevaron a su padre a rechazar ese libro. El narrador descubre en este proceso la traición cometida por su padre y llega a comprenderlo mejor y quizás a perdonarlo.

Si bien Los informantes no alienta las moralejas ni las interpretaciones alegóricas, no es difícil verla sin embargo como una apología del realismo narrativo y una exaltación de la novela como forma de conocimiento. Dentro de esta visión "cognoscitiva" de la novela, el autor funciona como un "informante" en tres posibles sentidos de este vocablo: primero, como un delator oculto, transmisor de secretos e intimidades; segundo, como un periodista que investiga la verdad de un sucedido y la hace pública, y tercero, como un principio organizador del relato que le da una "forma" inteligible.

Si en Bolaño la figura del autor es -tomando prestado un título de Severo Sarduy- un testigo fugaz y disfrazado, y en Vásquez es un "informante" - delator, reportero o mero recurso narrativo- en la novela del argentino Patricio Pron $E l$ espíritu de mis padres sigue subiendo en la lluvia (2011) el autor aparece como un desmemoriado que usa la escritura como cura para su amnesia parcial. La novela narra la historia del asesinato de un hombre de condición humilde en una ciudad de provincias de la Argentina a través de la lectura y el análisis que hace el narrador de las notas y recortes que su padre periodista acumuló sobre el caso. Usando las notas, y sin poder contar con la ayuda de su padre, quien está enfermo de gravedad en el hospital, el narrador reconstruye la historia del crimen. De este modo, entiende la motivación adicional que tuvo su padre para investigar ese caso aparentemente banal: purgar su sentimiento de culpa por la desaparición durante la "guerra sucia" de la hermana del hombre asesinado.

El narrador-protagonista de El espíritu de mis padres... es prácticamente idéntico a Pron: como este, padece de episodios amnésicos causados por el consumo de ansiolíticos (Koch 2013), vivió expatriado en Alemania, practica el periodismo y su padre es identificado con el mismo apodo y apellido que el padre del autor: "Chacho" Pron (Pron 2011: 95, 198). De hecho, el epílogo de la novela afirma que lo que en ella se narra son mayormente hechos documentables, aunque advierte que otros de esos hechos "son producto de las necesidades del relato de ficción" (198), e incluye, sorpresivamente, la dirección de una página de Internet donde el padre de Patricio Pron ofrece su propia versión de los sucesos narrados en la novela (198).

La imagen del "autor como hijo" aparece de nuevo en esta novela, pero esta vez asumida con plena humildad y en un contexto despojado del antagonismo patriarcal que se observa en Los informantes. Por el contrario, resulta significativo el hecho de que en la novela de Pron la figura autorial del narradorprotagonista aparezca reincorporándose a su familia y a su nación luego de una larga ausencia en el extranjero, renovando lazos afectivos y buscando reconectar las piezas del "rompecabezas nacional" -imagen que figura en la novela (129, 143) - para así poder seguir con su vida. Como observa el narrador hacia el final de la novela:

[M]i padre y yo estábamos buscando a una persona, yo a mi padre y él a Alberto Burdisso pero también y sobre todo, a Alicia Burdisso, que había sido su 
amiga durante la adolescencia y que, como él, militó durante el periodo del que estamos hablando y fue periodista y murió. Mi padre había comenzado a buscar a su amiga perdida y yo, sin quererlo, había empezado también poco después a buscar a mi padre y ese era un destino argentino. (Pron 2011: 184)

Como se ve, la variedad de usos, matices e implicaciones de la autoficción la han hecho, con sobrada razón, un artificio muy favorecido por los autores de estas primeras décadas del siglo xxI. De manera paradójica, justamente cuando el autor latinoamericano abandona su imagen heroica, este se torna más visible en su obra, pero a su vez esta visibilidad viene acompañada de una impresión de vulnerabilidad. Parecería entonces que, a través de la autoficción el autor latinoamericano de hoy se "destapa" dentro de su ficción, despojándose de su autoridad, revelándose como un ciudadano cualquiera, como un individuo muy semejante a sus lectores, y de hecho, como otro lector más. No obstante, como he querido sugerir con el epígrafe de "Examen de la obra de Herbert Quain" de Borges, la situación es más compleja: por un lado, se puede argumentar que la mayor visibilidad actual del autor dentro de su ficción es una reafirmación de su existencia e incluso de su vitalidad; al bajarse de su pedestal, la figura del autor en la autoficción se desparrama por su obra y se aferra aún más firmemente al texto con el cual aparece entretejida, pues obliga a los lectores a hacer referencia al contexto biográfico del autor al interpretar la obra. Por otra parte, sin embargo, la apariencia desvaída de la figura autorial en los textos que cultivan la autoficción parece alentar la ilusión de que todos podemos ser autores, de que basta con poner por escrito los materiales de nuestra siempre interesante biografía para crear un texto que muchos quieran leer. Según observa Patricio Pron en un ensayo sobre César Aira, el uso (y acaso el abuso) actual de la autoficción viene apoyado por "la pérdida de un pudor que en el pasado hizo que el escritor protegiese su intimidad adoptando la ficción esencialmente literaria de ser otro" (2010: 118). Pron también alude a la boga de los "reality shows" de la televisión (119), a lo cual habría que añadir además aquellas modalidades de Internet donde algunos ponen sus vidas en escaparate para disfrute o escarnio de amigos y enemigos: las redes sociales como Facebook y los blogs de variada índole.

A su vez, y como argumentan algunos, la cultura posmoderna ha promovido lo que se ha venido a llamar una "cultura del remix" que va más allá del mero eclecticismo, la parodia, o el collage. Según lo explica Eduardo Navas:

En términos generales, la cultura del remix puede definirse como una actividad global que consiste en el intercambio eficiente y creativo de información hecho posible por las tecnologías digitales. El remix se apoya en la práctica del cortar/ copiar y pegar. La noción del remix que conforma esta cultura se deriva del modelo de los remixes musicales producidos a fines de los 1960 y principios de los 70 en la ciudad de Nueva York, con raíces en la música de Jamaica. Durante la primera década del siglo xxl, el remix (la actividad de tomar muestras de materiales preexistentes para combinarlos en nuevas formas de acuerdo con el gusto individual) es ubicuo en el arte y la música, y cumple un papel esencial en las comunicaciones de masa, sobre todo en los nuevos medios digitales. (Navas 2012: 65; traducción mía) 
Michelle Knobel y Colin Lankshear (2011: 106), en su artículo "Remix: la nueva escritura popular", señalan además que una de las manifestaciones textuales más notorias del remix en la cultura popular es la llamada escritura de fanfiction. La misma consiste en el uso de personajes, ambientes y situaciones de series televisivas de culto (como Star Trek) por parte de los aficionados a ellas para crear sus propias ficciones, haciendo caso omiso de los derechos de autor, diseminándolas al principio en folletos impresos y más recientemente por Internet (Knobel y Lankshear 2011: 106). Un fenómeno semejante, aunque acaso más discreto, se observa en la reciente boga hispánica y latinoamericana de la novela negra, la cual se apropia abiertamente de temas, tramas, ambientes y rasgos estilísticos de las novelas detectivescas norteamericanas de los años 1930 a los 1950 al estilo hard-boiled de autores como Dashiel Hammett y Raymond Chandler. Otro ejemplo de la apropiación de elementos característicos de las obras de un autor de culto lo es el uso por parte del colombiano Santiago Gamboa, en su reciente novela Plegarias nocturnas (2012), de personajes del mundo diplomático e intrigas en ambientes urbanos del lejano oriente, a la manera de las novelas del inglés Graham Greene. (Claro está, el propio Gamboa ha sido diplomático en la India, por lo cual su novela tiene también mucho de autoficción.)

La apropiación y manipulación digital de los textos por medio de la función de "cortar y pegar" de nuestras computadoras ha problematizado la idea y el estatuto legal del plagio y ha llegado a normalizar la noción -muy bien conocida por los lectores de Borges y los teóricos de la literatura- de que todo texto es en el fondo un tejido de citas. Dentro de este concepto, la construcción legal del autor como dueño de su obra, sobre la cual le asisten "derechos de paternidad", se ha venido cuestionando cada vez más en la última década, por ejemplo en los trabajos del activista, profesor de leyes de Harvard y fundador del "Creative Commons", Lawrence Lessig5.

El vaticinio de Herbert Quain con respecto a los europeos en el relato de Borges parece haberse cumplido con creces y extendido al mundo entero: hoy día no hay nadie que no sea un escritor, en potencia o en acto. Dicho de otra manera, los lectores se extinguen porque ya pocos quieren ser lectores en el sentido riguroso de la palabra: lectores dispuestos a leer con paciencia y atención devota; en cambio, todos quieren ser leídos, aunque sea del modo presuroso que exigen los nuevos soportes materiales de la escritura. Esta es la realidad a la que se enfrentan los autores de hoy en nuestro mundo cibernético y globalizado: la de tener que convivir con sus conciudadanos en un plano de igualdad cotidiana, porque, como decía a fines del siglo xIx el modernista mexicano Manuel Gutiérrez Nájera, "ninguno cree que puede ser un hombre de talento el amigo con quien acaba de jugar al billar" (Carter 1974: 17).

\footnotetext{
${ }^{5}$ Véase en particular su libro The Future of Ideas: The Fate of the Commons in the Connected World (2002).
} 


\section{OBRAS CITADAS}

Alberca, Manuel (2007): Pacto ambiguo: de la novela autobiográfica a la autoficción. Madrid, Biblioteca Nueva.

Álvarez, Jesús Timoteo, y Martínez Riaza, Ascención (1992): Historia de la prensa hispanoamericana. Madrid, Editorial MAPFRE.

Barthes, Roland (1977): Image/Music/Text. Nueva York, Hill \& Wang.

Bolaño, Roberto (2009): Los detectives salvajes. Barcelona, Anagrama.

Borges, Jorge Luis (1996a): Obras completas I. Barcelona, Emecé.

- (1996b): Obras completas II. Barcelona, Emecé.

Bryce Echenique, Alfredo (1987): La vida exagerada de Martín Romaña. Barcelona, Plaza \& Janés.

Carter, Boyd G. (1974): "Estudio preliminar". En: Divagaciones y fantasías: Crónicas de Manuel Gutiérrez Nájera. México, SepSetentas, pp. 1-18.

Chihaia, Matei (2010): "Bolaño y yo. Las dos caras de la autoficción en Roberto Bolaño". En: Vera Toro, Sabine Schlickers y Ana Luengo (eds.): La obsesión del yo: la auto(r)ficción en la literatura española y latinoamericana. Madrid/Frankfurt, Iberoamericana/ Vervuert, pp. 141-154.

Covarsí, Jaime (2010): "Antecedentes socioculturales del relato autoficcional renacentista". En: Vera Toro, Sabine Schlickers y Ana Luengo (eds.): La obsesión del yo: la auto(r)ficción en la literatura española y latinoamericana. Madrid/Frankfurt, Iberoamericana/Vervuert, pp. 97-110.

Darrieussecq, Marie (1996): "L'autofiction, un genre pas serieux". En: Poétique, n. 107, pp. 369-380.

Donoso, José (1983): Historia personal del "Boom". Barcelona, Seix Barral.

Flaubert, Gustave (1980): The Letters of Gustave Flaubert 1830-1857. Selección, edición y traducción de Francis Steegmuller. Cambridge, MA, Harvard UP.

García Márquez, Gabriel (1981): Crónica de una muerte anunciada. Bogotá, Oveja Negra.

Gasparini, Philippe (2008): Autofiction. Une aventure du langage. París, Seuil.

González, Aníbal (2007): A Companion to Spanish American Modernismo. Londres, Tamesis. (2010): Love and Politics in the Contemporary Spanish American Novel. Austin, University of Texas Press.

Gutiérrez-Mouat, Ricardo (1988): "La narrativa latinoamericana del posboom". En: Revista Interamericana de Bibliografía / Inter-American Review of Bibliography, n. ${ }^{\circ} 38, \mathrm{pp}$. 3-10.

Knobel, Michelle, y Lankshear, Colin (2011): "Remix: la nueva escritura popular". En: Cuadernos Comillas: Revista Internacional de Aprendizaje del Español, n. ${ }^{\circ} 1$, pp. 105126.

Koch, Tommaso (2013): "Muchos autores en este momento están escribiendo el mismo libro: El argentino Patricio Pron publica el conjunto de relatos La vida interior de las plantas de interior". En: El País, 5 de febrero. Disponible en <http://cultura. elpais.com/cultura/2013/01/29/actualidad/1359481827_87779.html>. Última visita: 28.04.2013.

Lejeune, Philippe (1975): Le Pacte autobiographique. París, Seuil. 
Lessig, Lawrence (2001): The Future of Ideas: The Fate of the Commons in the Connected World. Nueva York, Vintage Books.

Molero de la Iglesia, Alicia (2000): La autoficción en España: Jorge Semprún, Carlos Barral, Luis Goytisolo, Enriqueta Antolín y Antonio Muñoz Molina. Berna, Peter Lang.

Navas, Eduardo (2012): Remix Theory: The Aesthetics of Sampling. Nueva York / Viena, Springer/Verlag.

Pellón, Gustavo (1996): "The Spanish American Novel: Recent Developments, 1975-1990". En: Roberto González Echevarría y Enrique Pupo-Walker (eds.): The Cambridge History of Latin American Literature 2: The Twentieth Century. Cambridge, Cambridge UP, pp. 279-302.

Pron, Patricio (2010): "De qué hablamos cuando hablamos de autor: la autoficción de César Aira en Cómo me hice monja". En: Vera Toro, Sabine Schlickers y Ana Luengo (eds.): La obsesión del yo: la auto(r)ficción en la literatura española y latinoamericana. Madrid/Frankfurt, Iberoamericana/Vervuert, pp. 111-122.

(2011): El espíritu de mis padres sigue subiendo en la lluvia. Barcelona, Mondadori.

Salazar, Diego (2013): "Juan Gabriel Vásquez: Los informantes. Entrevista". En: Club Cultura. Disponible en <http://www.clubcultura.com/clubliteratura/jgvasquez>. Última visita: 02.10.2013.

Saldívar, Dasso (1997): Gabriel García Márquez: El viaje a la semilla. La biografía. Madrid: Alfaguara.

Schlickers, Sabine (2010): "El escritor ficcionalizado o la autoficción como autor-ficción". En: Vera Toro, Sabine Schlickers y Ana Luengo (eds.): La obsesión del yo: la auto(r)ficción en la literatura española y latinoamericana. Madrid/Frankfurt, Iberoamericana/ Vervuert, pp. 51-72.

Shaw, Donald L. (1994): Antonio Skármeta and the Post-Boom. Hanover, NH, Ediciones del Norte.

(1998): The Post-Boom in Spanish American Fiction. Nueva York, State University of New York P.

Toro, Vera, Schlickers, Sabine, y Luengo, Ana (eds.): La obsesión del yo: la auto(r)ficción en la literatura española y latinoamericana. Madrid/Frankfurt, Iberoamericana/Vervuert.

Vásquez, Juan Gabriel (2004): Los informantes. Madrid, Alfaguara. (E-Book.)

Villena Garrido, Francisco (2009): Las máscaras del muerto: autoficción y topografías narrativas en la obra de Fernando Vallejo. Bogotá, Editorial de la Pontificia Universidad Javeriana. 